\title{
Diagnosing Small Duct Primary Sclerosing Cholangitis-A Rarer Variant of a Rare Disease: Challenges and Role of Liver Biopsy
}

\author{
Merina Rahman ${ }^{1}$, Abdullah A Mukit ${ }^{2}$, Faysal Ahmed ${ }^{3}$, Dulal C Das ${ }^{4}$, Sheikh M Noor-E-Alam5, Mamun A Mahtab ${ }^{6}$
}

\begin{abstract}
Primary sclerosing cholangitis (PSC), a disease of unknown etiology, is diagnosed on the clinical and biochemical findings of cholestasis combined with the characteristic findings seen on cholangiography. Small duct cholangitis is a variant of the PSC spectrum with distinct clinical course and outcome. We present two cases of small duct PSC, which are presented with the clinical and biochemical features of cholestasis but without typical positive findings on cholangiography. A liver biopsy was attempted, which confirmed sclerosing cholangitis. Upon diagnosis, both the patients were prescribed ursodeoxycholic acid at a dose of $15 \mathrm{mg} / \mathrm{kg}$ body weight/day and liver biochemistry was followed up after $3 \mathrm{months}$, which revealed biochemical improvement.

Being an uncommon variant of this "not so common" disease spectrum, small duct PSC often poses a diagnostic dilemma with its presentation due to the clinical and cholangiographic mismatch. The cases remind that a negative cholangiography does not rule out the PSC spectrum.

Keywords: Liver biopsy, Primary sclerosing cholangitis, Rare, Small duct, Ursodeoxycholic acid.

Bengal Physician Journal (2021): 10.5005/jp-journals-10070-7049
\end{abstract}

\section{INTRODUCTION}

Primary sclerosing cholangitis (PSC) is a cholestatic disease of unknown etiology characterized by chronic inflammation and fibrosis of the bile ducts. Despite being labeled as a rare disease, PSC, also known as large duct PSC, is a wellestablished disease entity. Thanks to the advent of endoscopic retrograde cholangiopancreatography and magnetic resonance cholangiogram (MRCP), there is now a better understanding of the disease prevalence and diagnostic convenience. The characteristic findings seen on cholangiography in the form of irregular bile ducts with multiple strictures and dilations giving rise to a "beaded pattern" are diagnostic of PSC. However, a minority of patients can be present with clinical and biochemical pictures similar to PSC, but lack typical findings on cholangiogram. These groups of patients require tissue diagnosis for the confirmation of diagnosis. Such cases that resemble PSC on biochemistry and histology, but appear normal on cholangiography, are termed small duct PSC. The negative cholangiogram finding is due to the fact that ducts can be too small to be detected on cholangiography and only be visible via biopsy. ${ }^{1}$ Small duct PSC represents around 5 to $20 \%$ of the whole PSC group. ${ }^{2-5}$ Compared to the classic PSC or large duct PSC, it has a more benign outcome. ${ }^{5}$ Also, it responds better to the standard therapy. ${ }^{1}$ A liver biopsy, thus, should be attempted to make a prompt diagnosis in cases that resemble PSC on laboratory workup, but end up with a normal cholangiogram. We report two cases of small duct PSC with similar initial diagnostic dilemma. The liver biopsy yielded the final diagnosis in this context.

\section{Case Descriptions}

\section{Case 1}

A 44-year-old hypertensive and diabetic woman presented with fatigue, pruritus, and mild jaundice with cholestatic liver

\footnotetext{
${ }^{1-6}$ Department of Hepatology, Bangabandhu Sheikh Mujib Medical University, Dhaka, Bangladesh

Corresponding Author: Mamun A Mahtab, Department of Hepatology, Bangabandhu Sheikh Mujib Medical University, Dhaka, Bangladesh, Phone: +8801711567275, e-mail: shwapnil@agni.com

How to cite this article: Rahman M, Mukit AA, Ahmed $F$, et al. Diagnosing Small Duct Primary Sclerosing Cholangitis-A Rarer Variant of a Rare Disease: Challenges and Role of Liver Biopsy. Bengal Physician Journal 2021;8(1):24-28.

Source of support: Nil

Conflict of interest: None
}

function tests. She gave no history of prodromal symptoms, abdominal pain, previous jaundice, hematemesis, melena, diarrhea, per rectal bleeding, and alteration of consciousness. She denied ever using tobacco products, alcohol, or illicit substances; nor did she take any drug prior to this illness except insulin and calcium channel blockers, which she had been taking for diabetes mellitus and hypertension, respectively. Examination revealed mild anemia, mild jaundice, and excoriations in different parts of the body due to pruritus.

All viral markers were negative, and the autoimmune profile was non-contributory, except for a positive finding of ASMA. MRCP showed no hepatobiliary abnormality. (Fig. 1 and Fig. 2) She was requested to be hospitalized for further evaluation. She was provisionally diagnosed as a case of small duct PSC. Our differential diagnosis was antimitochondrial antibodynegative primary biliary cholangitis. After necessary workup, a liver biopsy was performed. Histopathology report confirmed cholestatic hepatitis due to sclerosing cholangitis (Fig. 3 and Fig. 4). 

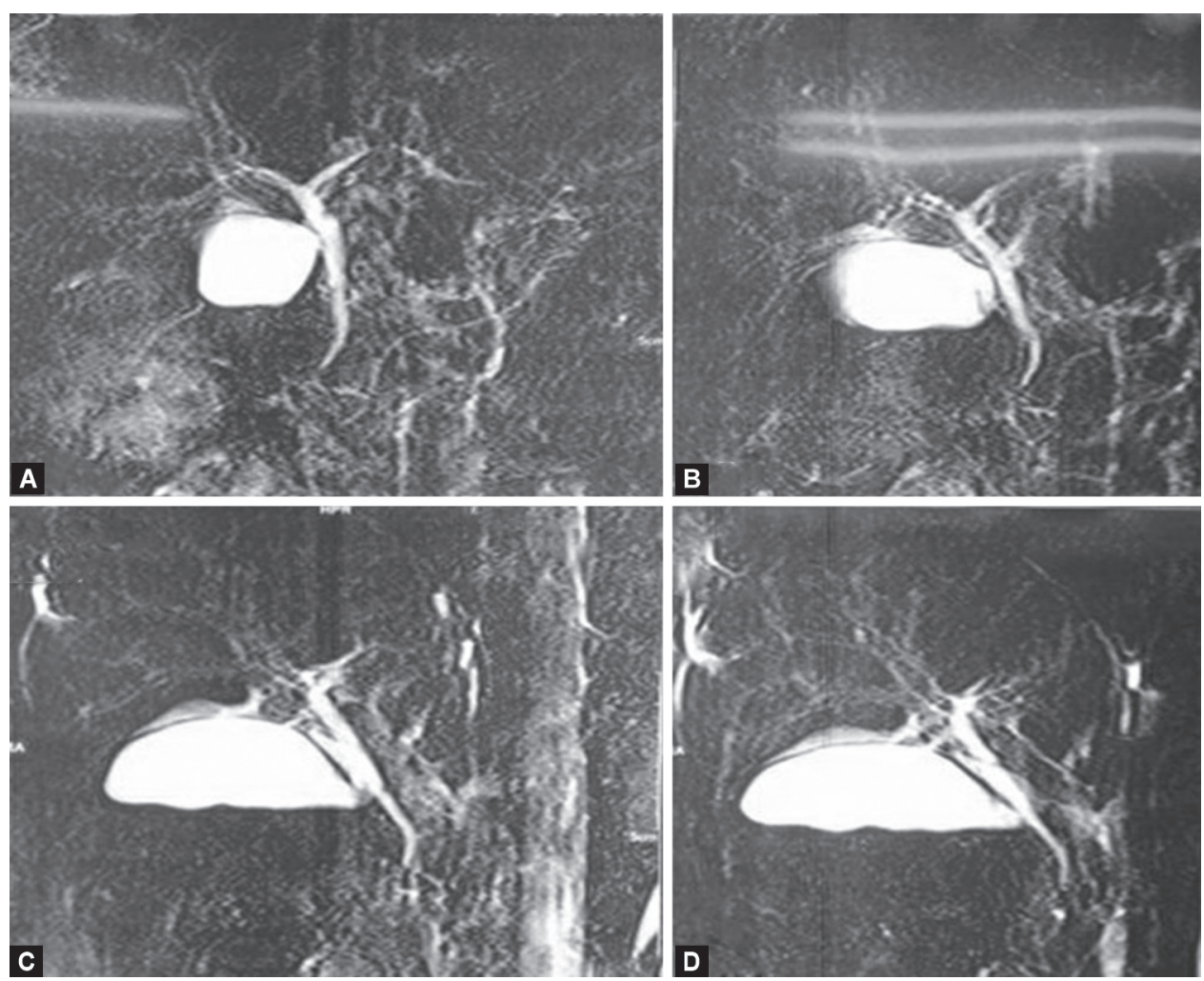

Fig. 1: MRCP reveals normal hepatobiliary anatomy (Case 1)
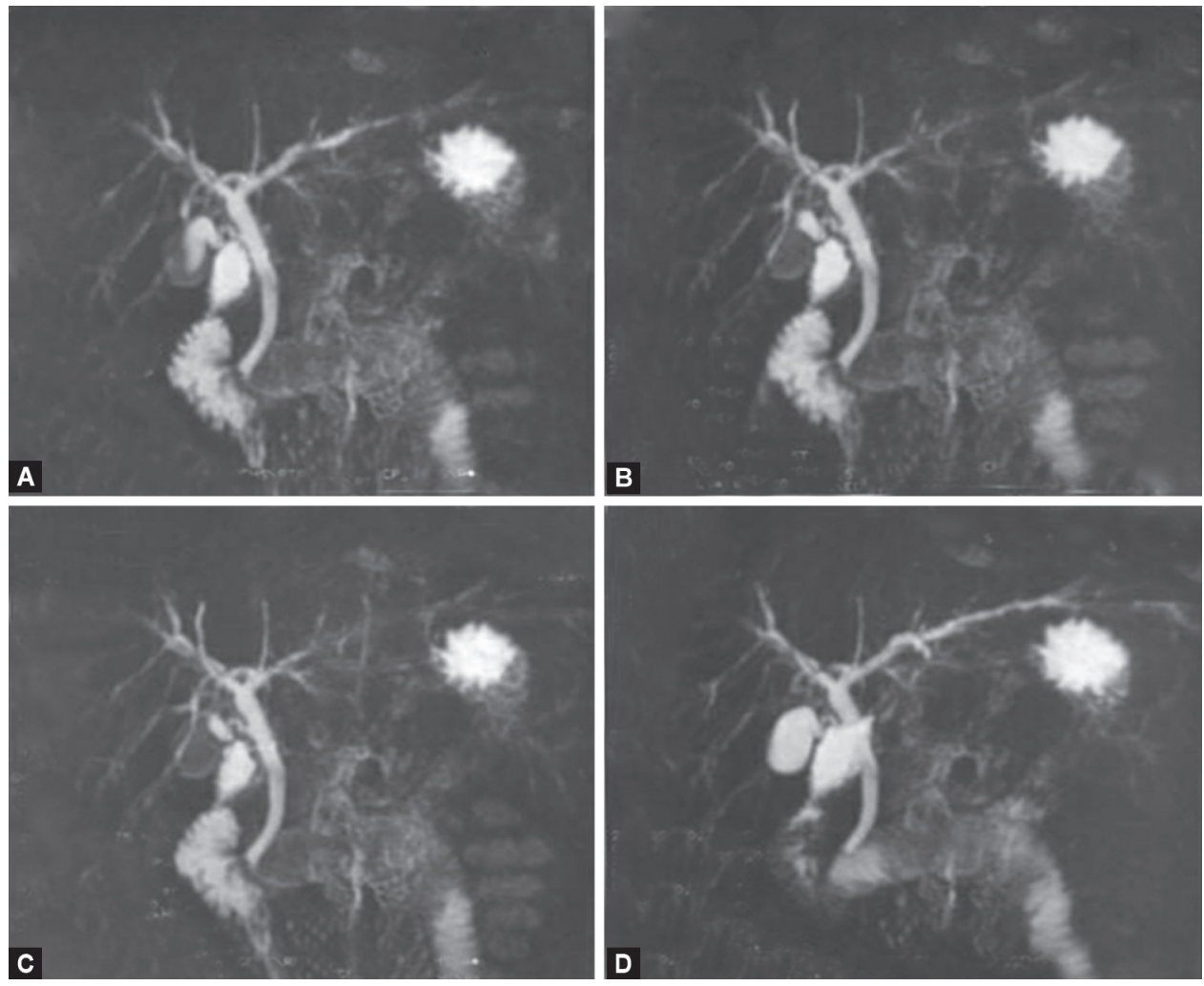

Fig. 2: MRCP reveals normal hepatobiliary anatomy (Case 2) 


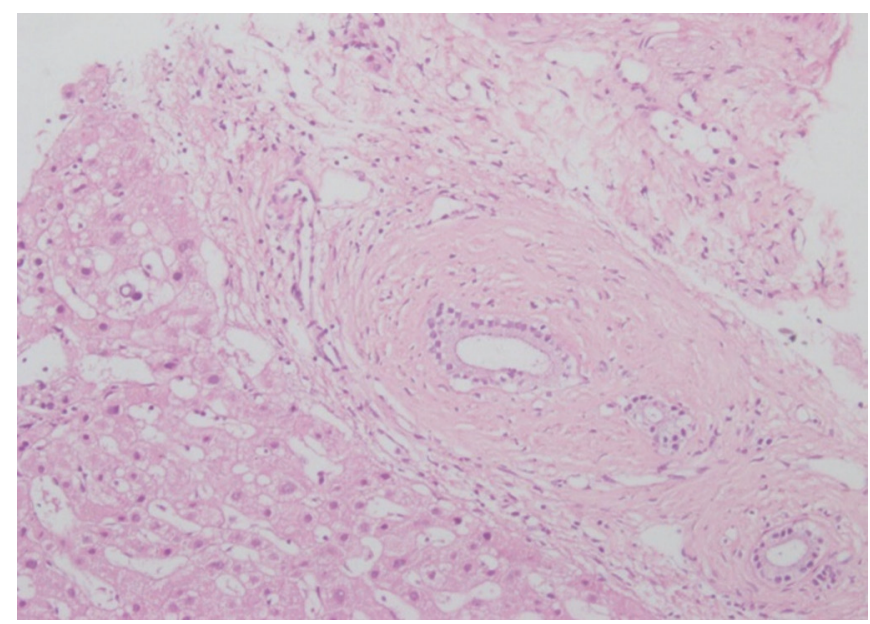

Fig. 3: Histopathology of the liver (Case 1) reveals mild periportal fibrosis and periportal inflammation including few polymorphs. Concentric fibrosis around bile ducts in one portal duct area is seen

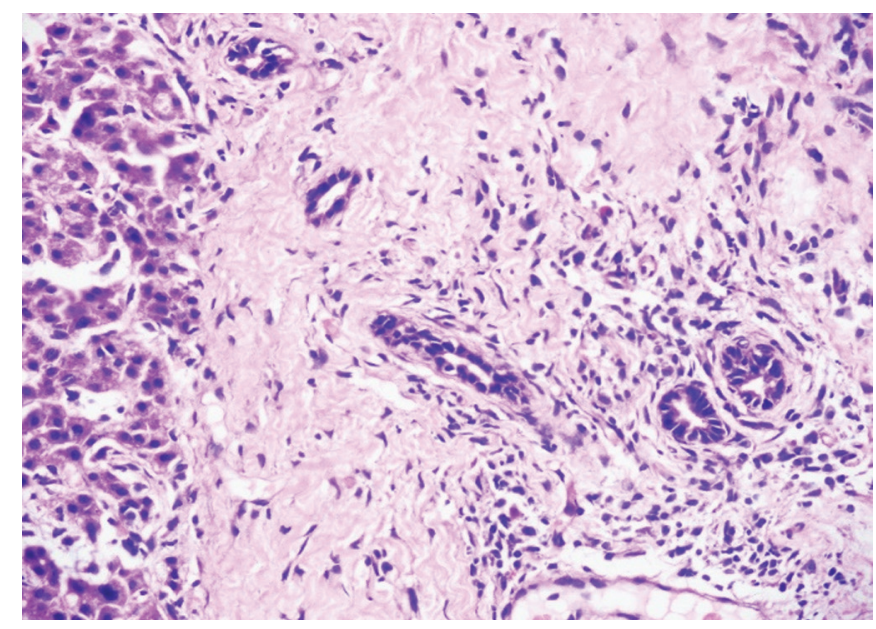

Fig. 4: Histopathology of the liver (Case 2) reveals the portal area showing moderate fibrosis with moderate infiltration of chronic inflammatory cells. A small number of eosinophils are present. Bile ductules in the portal area show invasion by inflammatory cells and occasional periductal accentuation of fibrous tissue.

\section{Case 2}

A 23-year-old normotensive, non-diabetic young woman presented with similar clinical features and cholestatic liver biochemistry. The examination revealed mild anemia, moderate jaundice, and several scratch marks. Viral markers and autoimmune profiles were negative. MRCP findings were within the normal limit. Like the previous case, liver biopsy was performed and histopathology report was compatible with sclerosing cholangitis.

Upon exclusion of secondary causes of sclerosing cholangitis, both cases were diagnosed as small duct PSC. UDCA, at a dose of $15 \mathrm{mg} / \mathrm{kg} / \mathrm{BW} /$ day, was given in divided doses, and the patients were advised to return for a follow-up after 3 months (Tables 1 and 2).

At the follow-up visit after 3 months, our first patient was clinically anicteric, pruritus resolved, and fatigue subsided to a great extent. On the contrary, during her follow-up visit, our second patient was mildly icteric, fatigue, and pruritus subsided. The liver biochemistry of both patients improved when compared to baseline values.

\section{Discussion}

Small duct PSC is a variant of the PSC spectrum. The epidemiology, natural history, and outcome of small duct PSC vary distinctly from those of the "classical" or "large duct" variants. While large duct PSC is more prevalent among women, the incidence of small duct PSC is more common among men. ${ }^{6}$ The median age at onset in both variants is around 38 years, ${ }^{5}$ although age was not shown to have an effect on the incidence or prognosis. ${ }^{6}$

An association with inflammatory bowel disease (IBD) is an important feature of PSC. The association appears to be more prevalent in the northern latitude ranging around 60 to $80 \%$. In Asia and southern Europe, the association is comparatively lower (34-60\%). However, the frequency of concurrent IBD is decreasing, even in the northern latitude. ${ }^{7-10}$

The presentation of PSC can be with pruritus, abdominal pain, fatigue, jaundice, and weight loss. In patients with small duct PSC, the most common symptoms are fatigue and pruritus, ${ }^{11}$ which is similar to the presentation of our patient. PSC is a progressive disease that can lead to cirrhosis. Cholangiocarcinoma is the most feared and frequent complication of PSC, although liver failure and colorectal carcinoma are not uncommon. ${ }^{9}$ Small duct PSC, on the contrary, is associated with a better long-term prognosis and long-term transplantation-free survival when compared with large duct PSC. ${ }^{5}$ Small duct PSC may progress to large duct PSC. According to three follow-up studies regarding small duct PSC, $12-17 \%$ patients with small duct PSC progressed to large duct PSC. ${ }^{4}$ Cholangiocarcinoma does not seem to complicate small duct PSC, unless the disease progresses to large duct PSC. Endstage liver disease can develop in patients with small duct PSC necessitating liver transplantation, even without the evidence of progression to large duct PSC. The recurrence of the disease can occur in allograft after liver transplantation. ${ }^{5}$

Liver biopsy has a crucial role in diagnosing small duct PSC. Unlike large duct PSC, small duct PSC lacks typical findings on cholangiogram. Hence, tissue diagnosis is necessary for small duct PSC. Histological specimen reveals inflammation and concentric fibrosis of the bile ducts. Marked periductal fibrosis can give rise to the characteristic "onion skin appearance," which is not a very common finding, but when present, is considered as the hallmark of PSC. ${ }^{12}$

Owing to the paucity of small duct PSC cases, there is a scarcity of information regarding medical treatment. However, UDCA, a widely used hydrophilic bile acid in the treatment of cholestatic liver disease, is associated with the biochemical improvement in small duct PSC. ${ }^{11}$ Following up of our cases after 3 months of UDCA therapy did reveal biochemical improvement. However, UDCA cannot slow down or prevent disease progression. Liver transplantation is the only curative treatment option. ${ }^{12}$

The cases reported here aims to point out the fact that small duct PSC, although rare, is a growing entity now. Due to the paucity of cases, case reporting is important in the present context for a better understanding of the prevalence, early diagnosis, clinical course, and initiation of timely therapeutic management. 
Table 1: Small duct primary sclerosing cholangitis investigations

\begin{tabular}{|c|c|c|}
\hline Investigations & Findings (Case 1) & Findings (Case 2) \\
\hline Hemoglobin & $11.6 \mathrm{~g} / \mathrm{dL}$ & $12.9 \mathrm{~g} / \mathrm{dL}$ \\
\hline ESR & $20 \mathrm{~mm}$ in $1 \mathrm{st}$ hour & $61 \mathrm{~mm}$ in $1 \mathrm{st}$ hour \\
\hline White blood cell & $7.5 \times 10^{9} / \mathrm{L}$ & $10.29 \times 10^{9} / \mathrm{L}$ \\
\hline Platelet count & $380 \times 10^{9} / \mathrm{L}$ & $317 \times 10^{9} / \mathrm{L}$ \\
\hline Alanine aminotransferase (ALT) & $140 \mathrm{U} / \mathrm{L}$ & $87 \mathrm{U} / \mathrm{L}$ \\
\hline Aspartate aminotransferase (AST) & $155 \mathrm{U} / \mathrm{L}$ & $96 \mathrm{U} / \mathrm{L}$ \\
\hline Alkaline phosphatase & $985 \mathrm{U} / \mathrm{L}$ & $1287 \mathrm{U} / \mathrm{L}$ \\
\hline Gamma-glutamyl transferase & $98 \mathrm{U} / \mathrm{L}$ & $90 \mathrm{U} / \mathrm{L}$ \\
\hline Serum bilirubin (total) & $4.19 \mathrm{mg} / \mathrm{dL}$ & $7.7 \mathrm{mg} / \mathrm{dL}$ \\
\hline Direct bilirubin & $3.2 \mathrm{mg} / \mathrm{dL}$ & $5.5 \mathrm{mg} / \mathrm{dL}$ \\
\hline S. albumin & $3.6 \mathrm{~g} / \mathrm{dL}$ & $3.4 \mathrm{~g} / \mathrm{dL}$ \\
\hline Prothrombin time & 14.1 seconds & 16 seconds \\
\hline International normalized ratio (INR) & 1.18 & 1.35 \\
\hline Fasting blood sugar & $7.6 \mathrm{mmol} / \mathrm{L}$ & $5.4 \mathrm{mmol} / \mathrm{L}$ \\
\hline Blood sugar 2 hours $A B F$ & $11.8 \mathrm{mmol} / \mathrm{L}$ & $7.8 \mathrm{mmol} / \mathrm{L}$ \\
\hline Serum creatinine & $0.84 \mathrm{mg} / \mathrm{dL}$ & $0.74 \mathrm{mg} / \mathrm{dL}$ \\
\hline Hepatitis B surface antigen & Negative & Negative \\
\hline Hepatitis B core antibody (total) & Negative & Negative \\
\hline Hepatitis C antibody & Negative & Negative \\
\hline Anti-hepatitis $A$ virus $\lg M$ & Negative & Negative \\
\hline Anti-hepatitis E virus Ig $M$ & Negative & Negative \\
\hline Anti-nuclear antibody & Negative & Negative \\
\hline Anti-LKM antibody & Negative & Negative \\
\hline Anti-mitochondrial antibody & Negative & Negative \\
\hline Anti-smooth muscle antibody & Positive & Negative \\
\hline Immunoglobulin G & $16 \mathrm{~g} / \mathrm{L}$ & $25.2 \mathrm{~g} / \mathrm{L}$ \\
\hline P-ANCA & $3.9 \mathrm{U} / \mathrm{mL}$ & $3.10 \mathrm{U} / \mathrm{mL}$ \\
\hline C-ANCA & $3.0 \mathrm{U} / \mathrm{mL}$ & $2.95 \mathrm{U} / \mathrm{mL}$ \\
\hline Cancer antigen (CA) 19-9 & $40 \mathrm{U} / \mathrm{mL}$ & $19.2 \mathrm{U} / \mathrm{mL}$ \\
\hline USG of the whole abdomen & Normal study & Normal study \\
\hline Endoscopy of upper GIT & Gastric erosion & Normal study \\
\hline Colonoscopy & Normal & Multiple ulcers in the terminal ileum, biopsy reveals chronic ileitis. \\
\hline Magnetic resonance cholangiopancreatography & Normal study & Normal study \\
\hline
\end{tabular}

Table 2: Comparison between liver biochemistry at baseline and after 3 months of UDCA therapy

\begin{tabular}{lllll}
\hline & Case 1 & \multicolumn{2}{c}{ Case 2 } \\
\hline & Value after 3 months & & Value after 3 months \\
Baseline value & of UDCA therapy & Laboratory tests & Baseline value & of UDCA therapy \\
\hline $140 \mathrm{U} / \mathrm{L}$ & $50 \mathrm{U} / \mathrm{L}$ & Alanine aminotransferase & $87 \mathrm{U} / \mathrm{L}$ & $65 \mathrm{U} / \mathrm{L}$ \\
$155 \mathrm{U} / \mathrm{L}$ & $59 \mathrm{U} / \mathrm{L}$ & Aspartate aminotransferase & $96 \mathrm{U} / \mathrm{L}$ & $72 \mathrm{U} / \mathrm{L}$ \\
$985 \mathrm{U} / \mathrm{L}$ & $651 \mathrm{U} / \mathrm{L}$ & Alkaline phosphatase & $1287 \mathrm{U} / \mathrm{L}$ & $560 \mathrm{U} / \mathrm{L}$ \\
$98 \mathrm{U} / \mathrm{L}$ & $75 \mathrm{U} / \mathrm{L}$ & Gamma-glutamyl transferase & $90 \mathrm{U} / \mathrm{L}$ & $60 \mathrm{U} / \mathrm{L}$ \\
$4.19 \mathrm{mg} / \mathrm{dL}$ & $1.8 \mathrm{mg} / \mathrm{dL}$ & Serum bilirubin (Total) & $7.7 \mathrm{mg} / \mathrm{dL}$ & $3.1 \mathrm{mg} / \mathrm{dL}$ \\
$3.2 \mathrm{mg} / \mathrm{dL}$ & $1.3 \mathrm{mg} / \mathrm{dL}$ & Direct bilirubin & $5.5 \mathrm{mg} / \mathrm{dL}$ & $2.7 \mathrm{mg} / \mathrm{dL}$ \\
\hline
\end{tabular}

\section{References}

1. Deliwala S, Sundus S, Haykal T, et al. Small duct primary sclerosing cholangitis: an underdiagnosed cause of chronic liver disease and cirrhosis. Cureus 2020;12(3):e7298. DOI: 10.7759/cureus.7298 [Epub ahead of print].
2. Angulo P, Maor-Kendler Y, Lindor K. Small-duct primary sclerosing cholangitis: a long term follow up study. Hepatology 2002;35(6): 1494-1500. DOI: 10.1053/jhep.2002.33202.

3. Bjornsson E, Boberg K, Cullen S, et al. Patients with small duct primary sclerosing cholangitis have a favourable long term prognosis. Gut 2002;51(5):731-735. DOI: 10.1136/gut.51.5.731. 
4. Broome $\mathrm{U}$, Glaumann $\mathrm{H}$, Lindstom $\mathrm{E}$, et al. Natural history and outcome in 32 Swedish patients with small duct primary sclerosing cholangitis (PSC). J Hepatol 2002;36(5):586-589. DOI: 10.1016/s01688278(02)00036-3.

5. Bjornsson E, Olsson R, Bergquist A, et al. The natural history of small-duct primary sclerosing cholangitis. Gastroenterology 2008;134(4):975-980. DOI: 10.1053/j.gastro.2008.01.042.

6. Lindkvist B, Gullberg B, Bjornsson E, et al. Incidence and prevalence of primary sclerosing cholangitis in a defined adult population in Sweden. Hepatology 2010;52(2):571-577. DOI: 10.1002/hep.23678.

7. Saarinen $\mathrm{S}$, Olerup $\mathrm{O}$, Broome U. Increased frequency of autoimmune diseases in patients with primary sclerosing cholangitis. Am J Gastroenterol 2000;95(11):3195-3199. DOI: 10.1111/j.15720241.2000.03292.x.

8. Yanai $\mathrm{H}$, Metalon $\mathrm{S}$, Rosenblatt $\mathrm{A}$, et al. Prognosis of primary sclerosing cholangitis in Israel is independent of coexisting inflammatory bowel disease. J Crohns Colitis 2015;9(2):177-184. DOI: 10.1093/ecco-jcc/ jju013.

9. Boonstra K, Weersma RK, van Erpecum KJ, et al. Population-based epidemiology, malignacy risk and outcome of primary sclerosing cholangitis. Hepatology 2013;58(6):2045-2055. DOI: 10.1002/ hep. 26565 .

10. Kuo A, Gomel R, Safer R, et al. Characteristics and outcomes reported by patients with primary sclerosing cholangitis through an online registry. Clin Gastroenterol Hepatol 2019;17(7):1372-1378. DOI: 10.1016/j.cgh.2018.04.047.

11. Charatcharoenwitthaya P, Angulo P, Enders FB, et al. Impact of inflammatory bowel disease and ursodeoxycholic acid therapy on small-duct primary sclerosing cholangitis. Hepatology 2008;47(1):133-142. DOI: 10.1002/hep.21960.

12. Kerlsen TH, Boberg K. Sclerosing cholangitis. In: Sherlock's disease of the liver and biliary system. 13th ed. 2018. p. 341-354. 